\title{
Filosofia da ciência como ferramenta microeconômica
}

Fabio Barbieri

Universidade P. Mackenzie e Unifecap

\section{Palavras-chave}

microeconomia, atividade empresarial, metodologia, Hayek, Popper.

Classificação JEL B41, A12, B53.

\section{Key words}

microeconomics, entrepreneurship, methodology, Hayek, Popper.

JEL Classification B41, $A 12$, B53.

\section{Resumo}

A teoria neoclássica pressupõe conhecimento perfeito. A crítica hayekiana a essa teoria, por sua vez, afirma que esse conhecimento é resultado do processo competitivo e, portanto, não pode ser considerado como dado. O "Problema de Hayek" investiga sob que condições o conhecimento do agente se aproxima dos reais fundamentos de uma economia. A fim de solucionar o "Problema de $\mathrm{Ha}$ yek", o nosso artigo utiliza algumas idéias da literatura de metodologia da Ciência, conhecida como teoria do "crescimento do conhecimento" (Popper, Kuhn, Lakatos e outros). Essas idéias são utilizadas para se compreender como evolui o conhecimento dos agentes econômicos, em especial o dos empresários. Estes são vistos como ativos formuladores de teorias empresariais conjecturais criticadas no processo competitivo, não como agentes passivos que maximizam funções já conhecidas da teoria convencional. Utiliza-se a Filosofia da Ciência não para analisar metodologicamente a microeconomia, mas, sim, como ferramenta analítica pertencente à própria teoria econômica.

\section{Abstract}

Neoclassical theory assumes perfect knowledge. In turn, Hayekian criticism of this theory affirms that this knowledge is the result of the competitive process, and therefore cannot be considered as a given. The "Hayek Problem" investigates the conditions under which agents' knowledge approaches the true fundamentals of an economy. In order to solve this problem, our paper uses ideas taken from the methodology of science known as the "growth of knowledge" theory (Popper, Kuhn, Lakatos and others). These ideas are used to understand how agents' knowledge evolves, especially the knowledge of entrepreneurs. These are seen as active formulators of conjectural entrepreneurial theories that are criticized in the competitive process, and not as passive agents that maximize already known functions as in conventional theory. We use philosophy of science not to methodologically analyze microeconomics, but as an analytical tool that is part of economic theory. 


\section{1_Introdução}

As teorias científicas tendem a apresentar retornos decrescentes em relação ao tempo empregado em seu desenvolvimento. A riqueza de aplicações potenciais que marcava a "juventude" de uma teoria acaba por declinar em sua maturidade. Esse declínio, por sua vez, convida a um crescente questionamento de seus pressupostos básicos. No caso da Economia, esse questionamento foi acompanhado pelo interesse cada vez maior pela Filosofia da Ciência, na medida em que esta possa ajudar a entender e a superar a crise da teoria. O propósito deste trabalho, entretanto, não é fazer uma análise puramente metodológica da teoria econômica neoclássica, mas, sim, sugerir a utilização da literatura de Filosofia da Ciência como ferramenta da própria teoria, a fim de justamente contornar uma de suas limitações.

Essa limitação se refere à maneira como o conhecimento dos agentes econômicos é obtido. A teoria convencional supõe que os agentes econômicos têm conhecimento perfeito sobre alternativas oferecidas no mercado e deriva logicamente os preços e as quantidades de equilíbrio, sem se preocupar com o processo de correção de erros pelo qual as falíveis opiniões e expectativas dos agen- tes se aproximam ou não, ao longo do tempo, dos reais fundamentos da Economia, fundamentos esses supostos inicialmente como conhecidos pela teoria de equilíbrio. Em outros termos, ignora-se o aprendizado que resulta do processo competitivo que ocorre antes que se obtenha o equilíbrio nos mercados.

A Filosofia da Ciência, preocupada com a questão de como se dá o aprendizado científico e a evolução do conhecimento, pode ser utilizada para estudar o processo de aprendizado no mercado e, portanto, fornecer uma teoria que resolva o problema mencionado. Nos dois casos, Ciência e mercado, temos um processo de crescimento do conhecimento: num o crescimento do conhecimento teórico, e no outro o crescimento do conhecimento mercadológico das "circunstâncias particulares de tempo e lugar" (Hayek, 1945), que são relevantes para a formulação de planos de ação dos agentes e que levam à coordenação entre esses planos obtida no equilíbrio. Essa semelhança levou Bartley (1990) a afirmar, de forma provocativa, que a Epistemologia seria um ramo da Economia, uma vez que o conhecimento é apenas mais uma das muitas formas de riqueza que crescem no processo descrito pelos dois campos de investigação. 
Para uma análise desse episódio e do debate em torno do cálculo econômico no socialismo, ver Barbieri (2004).
Fica então evidente a utilidade de teorias de Filosofia da Ciência para estudar o aprendizado no mercado. De fato, Loasby (1986), ao notar que muitas das questões atuais da Economia são na verdade sobre conhecimento e que, cada vez mais, se tenta modelar a relação entre fatos e expectativas (por exemplo, na teoria das expectativas racionais), surpreende-se com a negligência quase total, nesse tipo de análise, da literatura do "crescimento do conhecimento" (CC), composto pelas obras de Popper, Kuhn, Lakatos, Feyarabend e outros.

Quanto ao uso dessa literatura, Harper (1996, p. 5) afirma que o emprego de teorias de metodologia no mercado não é apelar apenas para metáfora. Ele comenta Loasby:

What I wish to emphasize here is that the relationship between scientific and market processes is not just that of analogy, for the growth of knowledge is the subject of both.

Neste trabalho iremos inicialmente expor o problema do conhecimento nos mercados aludido acima, também conhecido como o "Problema de Hayek". Em seguida, veremos como podemos utilizar a literatura metodológica para resolver tal problema, culminando com uma visão popperiana da atividade empresarial. Concluiremos o artigo sugerindo, como generalização dessa idéia, a utilização da Epistemologia Evolucionária como ferramenta a ser utilizada na teoria econômica.

\section{2_O "Problema de Hayek"}

O problema do conhecimento foi formulado por Hayek como conseqüência de sua crítica feita na década de trinta ao uso da teoria neoclássica como instrumento de planejamento central. ${ }^{1}$ Autores como Dickinson e Lange acreditavam que, se os fundamentos da Economia (preferências, tecnologias, dotações de recursos) fossem dados, seria possível, com o auxílio da teoria de equilíbrio geral, encontrar preços-sombra de equilíbrio que guiassem a produção de firmas estatais no socialismo, sem a necessidade de mercados e preços reais.

No primeiro e mais importante de uma série de artigos sobre o problema do conhecimento - intitulado Economics and Knowledge (de 1937) -, Hayek argumenta que a descrição do estado de equilíbrio não consiste em uma explicação suficiente dos fenômenos de mercado. Tal descrição, denominada por Mises de "pura lógica da escolha", funda-se somente em derivações de resultados obtidos com base no conhecimento dos dados do problema no qual a escolha diante da es- 
cassez se faz necessária. Isso seria um exercício lógico, sem conteúdo empírico. Em uma economia com um agente isolado, tanto os meios como os fins da escolha econômica são dados subjetivos, imaginados pelo agente. Neste caso, não há grandes problemas sobre a correspondência entre dados e realidade. Mas, em uma economia com extensa divisão do trabalho, o plano de ação de cada indivíduo tem de levar em conta dados externos, como preferências dos outros consumidores, tecnologias e existências de recursos de posse de outras firmas, bem como os próprios planos de ação dessas firmas, e, para que haja equilíbrio, os planos de cada agente não podem ser incompatíveis entre si.

Hayek aponta então para um problema na transição da análise do indivíduo isolado para a interação entre vários deles, problema esse derivado das restritivas condições para que o equilíbrio ocorra. Cada agente teria de prever corretamente inúmeros aspectos do problema econômico que o cerca e, ao mesmo tempo, o comportamento dos demais agentes, que, por sua vez, tentam fazer o mesmo tipo de previsão. Isso aumenta sobremaneira a complexidade da tarefa de coordenar as ações individuais. Mas, como a capacidade cognitiva dos agentes é limitada, os dados subjetivos de cada agente não se identificam automaticamente como a realidade subjacente. O conhecimento dos agentes será então apenas conjectural, e, portanto, a análise econômica não pode mais seguir em bases puramente tautológicas, já que surge a possibilidade de conhecimento errado, incompatível com o equilíbrio.

$\mathrm{Na}$ teoria neoclássica, tal problema seria contornado pela suposição de que os mesmos "dados" são dados para todos os agentes. O conceito de "dado" teria então sofrido uma (não discutida) mudança de significado. As ambigüidades geradas pela mudança de significado surgem, por exemplo, na falta de clareza sobre se "dado" significa conhecimento objetivo, supostamente conhecido pelo economista, ou se significa conhecimento subjetivo dos agentes, e nesse caso se esse conhecimento é o mesmo para todos os agentes.

$\mathrm{O}$ ponto central da crítica de $\mathrm{Ha}$ yek consiste na afirmação de que os economistas simplesmente supõem a correspondência entre dados subjetivos e realidade objetiva, ignorando o processo de mercado que explicaria como essa correspondência é obtida. Se a teoria econômica pretende oferecer explicações reais sobre o funcionamento dos mercados, 
deve-se estudar o processo pelo qual as expectativas se tornam corretas e as condições para que se obtenha um equilíbrio no qual os planos se tornam compatíveis. Hayek considera de fato que a existência de coordenação nos mercados é uma regularidade empírica e que deve então ser explicada com a ajuda de uma teoria sobre o aprendizado dos agentes.

Essa explicação, como argumentamos neste trabalho, pode ser feita com o auxílio da literatura de Filosofia da Ciência, que estuda o mesmo problema em outro contexto. O problema posto acima, denominado o "Problema de $\mathrm{Ha}$ yek", não encontra no artigo de 1937 uma solução explicitamente calcada na metodologia, embora o autor seja ele mesmo um estudioso do assunto. Nos artigos subseqüentes, porém, o problema continua a ser investigado e fornece fragmentos da solução que pretendemos. Em The Uses of Knowledge in Society (de 1945), Hayek mostra como o problema do conhecimento é resolvido nos mercados mediante o uso do sistema de preços, que guia a ação dos agentes sem que esses tenham que dominar todo o conhecimento necessário para que a coordenação entre eles ocorra. É possível assim obter coordenação mesmo que o conhecimento seja altamente disperso entre os agentes.
Além dessa "economia de conhecimento" proporcionada pela interpretação dos preços pelos agentes, o mecanismo de lucros e perdas premia e pune ações baseadas em conjecturas empresariais corretas ou incorretas. Temos assim a base do mecanismo de correção de erros necessário para uma teoria de aprendizado nos mercados.

Em The Meaning of Competition (de 1946), Hayek reafirma a necessidade de estudar o processo de aprendizado empresarial, ignorado pela teoria da competição perfeita, que, ao estudar apenas o estado final de equilíbrio, deixa de lado o próprio mecanismo competitivo que permite que esse equilíbrio seja obtido. De fato, para Hayek, a verdadeira função desempenhada pela competição tende a ser ignorada pelos economistas, quando, na formulação do problema alocativo, parte-se de um estoque "dado" de bens:

The real problem in all this is not whether we will get given commodities or services at given marginal costs but mainly by what commodities and services the needs of the people can be most cheaply satisfied. The solution of the economic problem of society is in this respect always a voyage of exploration into the unknown, an attempt to discover new ways of doing things better than they have been done before (Hayek, 1980c, p. 100-101). 
O "Problema de Hayek" convida então a desenvolvermos a teoria da atividade empresarial, na qual a competição se refere à criação e à descoberta de oportunidades de lucros advindas de ação baseada em conjecturas rivais sobre aqueles fundamentos da Economia que são vistos como dados de início pela teoria da competição perfeita.

A teoria da atividade empresarial naturalmente sugere o uso da Filosofia da Ciência. De fato, em Competition as a Discovery Procedure, Hayek (1978, p. 256) traça um paralelo entre o aprendizado nos mercados e o progresso científico: nas duas esferas temos pessoas (agentes, cientistas) que buscam entender seu objeto de interesse; enquanto na Ciência se investigam leis gerais, no mercado se busca descobrir fatos mercadológicos particulares a cada situação. Nesse artigo, fica claro que as alternativas existentes no mercado não são dadas ou conhecidas, mas criadas e descobertas ao longo do processo competitivo, e não há como saber de antemão quais serão as soluções encontradas pelos empresários ao longo desse processo. Assim, o mecanismo de coordenação das atividades dos agentes proporcionado pelo sistema de preços é valorizado pelo autor mais pela sua capacidade de gerar conhecimento novo do que pela possibilidade de esgotar completamente os ganhos de troca.

Os argumentos de Hayek desenvolvidos aqui podem ser interpretados em termos popperianos, visto que a crítica e a competição oferecem, na Ciência e no mercado, mecanismos de correção de hipóteses conjecturais. No processo de mercado, para Hayek, já que o conhecimento prático dos agentes também tem natureza conjectural, é inevitável que ocorra a frustração de algumas expectativas diante da realização dos lucros, o que induz alterações nessas conjecturas, de maneira a ocorrer um aprendizado por tentativas e erros. Vejamos então como podemos usar a literatura do CC para estudar o aprendizado dos agentes.

\section{Economia do Conhecimento $x$ Economia da Informação}

A primeira aplicação da literatura do "crescimento do conhecimento" que faremos se refere à Economia da Informação. Essa disciplina, desde o pioneiro artigo de Stigler (1961), procura substituir o pressuposto de conhecimento perfeito da teoria tradicional por modelos que incorporam o aprendizado dos agentes econômicos, que assume a forma de aquisição de informações a um custo conhecido, 
cujo valor também é conhecido, seja em mercados de bens de informação, seja por coleta direta dos dados.

O desenvolvimento da Economia da Informação, ao reconhecer que os agentes possuem informação limitada, poderia levar à consciência da existência do problema do conhecimento de Hayek. De fato, alguns de seus expoentes modernos, como Grossman e Stiglitz (1996), reconhecem explicitamente a importância do artigo de Hayek de 1945 para o próprio programa de pesquisa. Examinando mais de perto, porém, vemos que esses autores sistematicamente distorcem o argumento de Hayek, tratando na verdade de problemas completamente diferentes. Isso se relaciona, como veremos, com a teoria do conhecimento subjacente aos problemas dos respectivos autores. Mais especificamente, enquanto a abordagem de Hayek sobre o conhecimento dos agentes é compatível com a literatura do CC, a abordagem de Grossman e Stiglitz é mais próxima de uma visão pré-popperiana de ciência. Curiosamente, as metodologias que os autores adotam para a própria Economia condicionam as concepções sobre o conhecimento dos agentes que povoam suas teorias.

$\mathrm{Na}$ metodologia pós-positivista, a Ciência não progride por meio do acú- mulo indutivo de informações objetivas coletadas sistematicamente e que corroboram ou confirmam novas conclusões adicionadas ao estoque de conhecimento já provado. Pelo contrário, parte-se de problemas diante dos quais se formulam hipóteses explicativas de natureza conjectural e falível. As informações coletadas para testar a teoria, por sua vez, são necessariamente influenciadas pelo conjunto de teorias prévias adotadas pelo observador (theory laden), de modo que uma mesma realidade externa pode ser vista e interpretada de maneira diversa por observadores distintos. O exame crítico de uma teoria, por outro lado, resulta na emergência de descobertas surpreendentes, na medida em que as hipóteses são modificadas, e suas conseqüências lógicas, exploradas. A evolução da Ciência é marcada não por progresso contínuo, mas pela periódica substituição de teorias bem estabelecidas por outras, sendo o processo de teste de teorias extremamente complexo e muitas vezes inconclusivo.

A concepção de Ciência descrita resumidamente acima, quando empregada para resolver o problema de Hayek, descreve perfeitamente o "processo de descoberta" imaginado por esse autor. Nesse processo, o sistema de preços é uma ferramenta fundamental que auxilia 
a eliminação de hipóteses erradas e a formulação de conjecturas empresariais. Grossman e Stiglitz, porém, traduzem o argumento para o referencial neoclássico, crendo que Hayek sustenta a idéia de que os preços de mercado são capazes de transmitir e agregar informações de forma eficiente. Todavia, levando-se em conta que a obtenção de informação é custosa, Grossman e Stiglitz (1996, p. 256) chegam à conclusão contrária do que teria afirmado Hayek.

Os autores desenvolvem um modelo no qual um ativo financeiro com retorno $r$ é demandado por agentes que podem ou não obter (a certo custo conhecido) informações sobre um parâmetro $\eta$ que se relaciona com o retorno, que, por sua vez, depende também de uma variável não observável $\varepsilon$. Temos assim:

$r=\eta+\varepsilon$

sendo $\eta$ e $\varepsilon$ variáveis aleatórias independentes. A demanda per capita dos agentes informados depende tanto do preço $\mathrm{p}$ quanto do valor de $\eta$, enquanto a demanda dos desinformados depende apenas dos preços. Em equilíbrio, a demanda de mercado se iguala à oferta. Quando a oferta for fixa, variações nos preços de equilíbrio são causadas por variações na demanda dos agentes informados que observaram valores diferentes de $\eta$. Os desinformados podem então inferir a partir de um aumento de preços, o aumento de $\eta$, isto é, os preços transmitiriam, de forma perfeita, informação dos informados para os desinformados. Quando o estoque do ativo varia aleatoriamente, uma mudança nos preços pode ser em razão tanto de alterações na demanda dos informados quanto de oscilações na oferta. Neste caso, os preços revelam alguma informação sobre $\eta$, mas não informação completa.

Considerando o custo de obter informação, ter-se-ia em equilíbrio que um indivíduo estaria indiferente entre obtê-la ou não. Quando o sistema de preços for informativo, porém, não vale a pena comprar informações sobre $\eta$, uma vez que se pode inferir gratuitamente seu valor pelo preço. No extremo oposto, quando nenhum agente conhece $\eta$, valeria a pena a compra da informação, já que o sistema de preços não informaria nada. Pode-se então chegar em equilíbrio a uma fração dos indivíduos em equilíbrio comprando informação e outra não. Nesse modelo, a afirmação "de Hayek" de que os preços transmitem informação de forma perfeita não se sustentaria.

Esse modelo ilustra perfeitamente o modo como, para boa parte dos economistas, os agentes aprendem no mercado. 
De algum modo, os agentes sabem exatamente quais informações são relevantes para a tomada de decisão, o seu valor e também seu custo. Nenhuma informação causa surpresa, alterando o conhecimento que o agente tem sobre a realidade. Supõe-se que os agentes já conhecem a teoria correta sobre o mundo; só faltam os dados para tomar as decisões. $\mathrm{O}$ aprendizado, dessa forma, dá-se por acúmulo indutivo de informações, sem a possibilidade de que o modelo sobre o retorno do ativo seja refutado, alterado ou que se criem opiniões rivais sobre quais fatores influenciam tal retorno. $\mathrm{O}$ conhecimento nunca é conjectural, falível ou controverso, apenas incompleto. Para Grossman e Stiglitz (1996), os preços não exercem o papel de, fora do equilíbrio, auxiliar o processo de descoberta de conhecimento. Desconsiderada essa função, o desempenho dos mercados é avaliado somente em termos da capacidade de gerar alocações ótimas.

Thomsen (1992, p. 61), em sua crítica a essa abordagem, identifica três diferentes funções informativas dos preços, a saber:

a. os preços permitem que os agentes tomem decisões como se possuíssem muito mais informação de que de fato possuem, segundo o argumento desenvolvido por Hayek em The Uses of Knowledge in Society;

b. os preços permitem que se façam inferências sobre conhecimento possuído por outros, conforme argumentam Grossman e Stiglitz;

c. preços em desequilíbrio fornecem oportunidades de lucros que induzem um processo de descoberta que produz conhecimento não antes imaginado, conforme o argumento de Hayek desenvolvido pela moderna abordagem de processo de mercado austríaca.

Thomsen procura mostrar que esta última função não diz respeito à possibilidade de resumir nos preços as informações dispersas na sociedade, mas, sim, ao fato de que, como apontou Lavoie (1985), os empresários aceitam alguns preços, mas discordam de outros, apostando recursos na hipótese de que seu conhecimento sobre características locais do mercado revele oportunidades de lucros não percebidas pelos demais agentes.

Diante da crítica hayekiana de que o conhecimento não é dado, a Economia da Informação simplesmente transfere um mercado para trás o pressuposto tácito de conhecimento não problemático, tanto na defesa dos mercados, feita por 
Stigler, quanto na sua crítica, feita por Stiglitz. No primeiro caso, os agentes não têm conhecimento perfeito, mas nível ótimo de ignorância. Contudo, como apontaram autores como Shacke, Lachmann e Kirzner, não é possível avaliar a utilidade de uma informação antes de adquiri-la, ${ }^{2}$ de forma que as decisões nesse mercado não são determinadas, mas dependem das crenças prévias de cada agente, e nada garante que essas crenças são corretas. No segundo caso, embora os agentes tenham informação incompleta, não se explica por que o modelo adotado por eles seria correto. Em ambos os casos, pressupõe-se em uma instância anterior a existência de conhecimento já confirmado pelo acúmulo de dados corroborados.

O contraste entre o problema do conhecimento de Hayek e a Economia da Informação nos leva à distinção entre informação e conhecimento proposta por inúmeros autores. A idéia de que o primeiro conceito se refere a um fluxo de dados objetivos e o segundo a um estoque de generalizações pode ser adaptada para contrastar a visão de aprendizado como acúmulo indutivo com a visão de aprendizado como modificações em estruturas hipotético-dedutivas falíveis. Em Economia, a primeira visão é dominante.
O conceito de racionalidade limitada de Simon, por exemplo, baseia-se na postura indutivista do conhecimento, reduzindo o problema do conhecimento a limitações na capacidade de processamento de informações. Os modelos de expectativas racionais também tratam o aprendizado desse modo.

Ao advogar a mesma distinção, Fransman (1998) elabora uma ilustração - o "paradoxo da IBM" - que merece ser reproduzida. Como uma firma, pergunta o autor, que era a processadora de informações por excelência, pôde cometer um erro estratégico fundamental, que levou à queda da hegemonia da empresa? A IBM acreditava que o setor de mainframes poderia manter a sua lucratividade. No entanto, ela dispunha dos dados que apontavam para o crescimento da parcela de mercado do setor de microcomputadores, que se tornou possível pelo avanço da tecnologia de microchips. Outros empresários, com menos capacidade computacional, tinham teorias melhores sobre o futuro do setor. Essa história ensina que devemos abandonar a idéia de conhecimento como informação processada. Tal visão errônea se baseia numa teoria do conhecimento justificacionista e indutivista, criticada há muito tempo por Popper. Não se tratou, portanto, de pro-
2 Por isso as aplicações tendem a ser em modelos de finanças, cuja incerteza pode ser reduzida ao valor esperado de alguns indicadores quantitativos prontamente especificáveis. 
3 Neste trabalho estaremos preocupados principalmente com os ganhos para a Economia que podem ser obtidos pela interação com a Metodologia. Os ganhos na outra direção são estudados, por exemplo, por Bartley (1990). blema de racionalidade limitada, mas da "teoria empresarial" errônea da direção da empresa, que, no caso, foi refutada pelo teste de mercado.

A visão da firma como uma tabula rasa na qual se imprimem informações que geram generalizações indutivas corroboradas está em flagrante contraste como todo o pensamento filosófico moderno. Tendo em vista essa história, Fransman define conhecimento como crença, que pode ser influenciada, mas não determinada, por informações. O elemento que Fransman introduz na teoria da firma é o conceito de visão, ou conjunto de crenças dominantes sobre a realidade relevante para a esfera de ação da firma. Conclui o autor que é necessário "analisar o processo de criação de conhecimento dentro da firma" (o processo de CC) e "tratar o conhecimento em seus próprios termos, como um processo aberto", lidando com o "Problema de Hayek" de integração de conhecimento disperso entre os membros da sociedade, mobilizando conhecimento tácito e articulado (Polanyi, 1958) e entender o processo criativo da ação dentro da firma.

Essa alternativa, contudo, esbarra com um problema: a formalização matemática (pelo menos a matemática usualmente empregada) não é neutra em relação à concepção filosófica empregada.
Como o conhecimento a ser descoberto pelo agente no modelo é especificado e representado por símbolos antes do aprendizado, este necessariamente assume caráter indutivo. De fato, a competição, como aponta Hayek (1978), tem o seu valor fundamental na capacidade de gerar conhecimento insuspeito até então. Contudo, por definição, esse não pode ser especificado de antemão. Avaliar o mercado apenas em termos de obtenção de equilíbrios eficientes, como faz Stiglitz, peca então por supor como dado algo que é fruto do próprio processo negligenciado pela teoria. Tem-se então uma petição de princípio.

Tendo em vista o que dissemos nesta seção, podemos afirmar como conclusão que a negligência da Filosofia da Ciência moderna tem como conseqüência a desconsideração da importância da atividade empresarial em que consiste a competição real nos mercados, em favor do comportamento passivo e paramétrico descrito pela teoria tradicional.

\section{4_Competição e os programas de pesquisa das firmas}

Uma evidência de que realmente existem ganhos de troca entre microeconomia e metodologia ${ }^{3}$ é fornecida pelo fato de que fragmentos da solução metodológica 
do "Problema de Hayek" que buscamos aparecem algumas vezes na literatura. Esses fragmentos podem ser divididos em dois grupos. O primeiro utiliza a metodologia de conjecturas e refutações de Popper, e o segundo, as abordagens mais históricas de Kuhn e Lakatos sobre a evolução das teorias científicas.

Essa divisão torna natural o uso das teorias destes últimos para investigar o "Problema de Hayek" no ambiente das firmas, à medida que o estudo das normas e costumes existentes nas organizações possa revelar o modo como certas teorias sobre o funcionamento dos mercados defendidas por diferentes grupos de executivos possam vir a dominar, evoluir ou ser substituídas por outras. A abordagem popperiana, por outro lado, é adequada para o estudo da competição, na medida em que a conjectura empresarial adotada por cada firma, e que guia a ação dela, é submetida a teste no processo competitivo.

As duas abordagens citadas acima aparecem em um artigo de Loasby, que passaremos a estudar em seguida. Loasby (1986) revê alguns aspectos das teorias de Popper, Kuhn e Lakatos e, em seguida, aplica-os à Economia, tendo em vista os problemas da firma e da competição já mencionados.
O autor utiliza Popper para traçar o paralelo entre a competição científica e a empresarial:

Scientists seek to advance knowledge, but can do so only by exposing their own ideas to the testing of their fellows and to comparison with other new ideas from other scientists - just as entrepreneurs, seeking to better existing offerings, must expose themselves to the appraisal of customers and suppliers, and to the risk of being surpassed by competitors' offers. This exposure is fatal to most new ideas, both of scientists and of entrepreneurs. Competitive science, like competition in the marketplace, is at once a discovery procedure and a control mechanism (Loasby, 1986, p. 43).

O mecanismo de eliminação de erros promovido pelo processo competitivo é integrado, no artigo em questão, com a necessidade de geração de hipóteses empresariais rivais, já que o reconhecimento da limitação do conhecimento dos agentes exige a diversidade de hipóteses submetidas a teste e o conseqüente aumento da probabilidade de que algumas delas sobrevivam à crítica, havendo assim aprendizado:

The proper argument for competition, in science as in business, as a mean to improve knowledge, is that it promotes alternative conjectures - and their critical examination (Loasby, 1986, p. 53). 
4 "The process of conjecture, testing and criticism which leads to the growth of knowledge is bopelessly inefficient if carried on by individuals in isolation" (Loasby, 1993, p. 205).
Esses paralelos ilustram claramente a epistemologia falibilista, que marca o pensamento tanto de Hayek quanto de Popper.

Além dos temas popperianos, Loasby explora as idéias de Kuhn e Lakatos. No mercado e na Ciência, nota o autor, a competição deve pressupor certa cooperação: ${ }^{4} \mathrm{O}$ teste deve ser realizado dentro de uma estrutura (framework), legal no caso do mercado e metodológica no outro. Neste último caso, a não-existência de testes crucias inequívocos e a tese Duhem-Quine levam à necessidade de que os testes se dêem dentro de uma estrutura de prática científica, marcada por regras de procedimento aceitas por uma tradição científica. As obras de Kuhn e Lakatos enfatizam esse tipo de estrutura, com os conceitos de paradigmas do primeiro autor e programas de pesquisa do segundo.

O mesmo vale em relação ao conhecimento no mercado, já que também ali não se testa uma hipótese isolada, mas um conjunto delas. A informação sinalizadora oferecida pelos preços praticados e pelas quantidades adquiridas, por exemplo, não tem uma única interpretação possível, quando várias forças de mercado atuam simultaneamente e não conhecemos todas elas. Podemos então perguntar como são formados, nos processos decisórios das firmas, procedimentos de avaliação de hipóteses empresariais diante da sucessão dos eventos nos mercados.

Loasby busca inspiração em Kuhn e Lakatos para responder a essa questão. No processo de resolução de problemas nos mercados, a existência de uma estrutura de análise, rígida o bastante para não ser abandonada diante de qualquer evidência empírica aparentemente refutadora e flexível o suficiente para se adaptar a novos problemas, contribui para o crescimento do conhecimento das firmas. Em seu artigo, Loasby (1986) direciona a sua atenção para o problema da coerência organizacional em termos de choques entre estruturas interpretativas diferentes. As firmas, vistas como "universidades visíveis" de "cientistas", devem manter uma estrutura interpretativa em comum apenas no que diz respeito às suas diretrizes fundamentais, podendo se beneficiar da flexibilidade advinda da multiplicidade de estruturas diferentes nos departamentos isolados, no que se refere aos problemas específicos de cada um deles. Ecoando Nelson e Winter (1982), o autor mostra a importância da adição de novos elementos na estrutura interpretativa das firmas, resultante da contratação de novos funcionários. 
Num segundo artigo, Loasby (1993) procura estender a análise da firma para a competição no mercado, enfatizando o papel das instituições como modificadores e norteadores das estruturas mencionadas no primeiro artigo. A estrutura institucional pode se alterar conforme aumentem a incerteza e as "anomalias" na estrutura interpretativa anterior. Isso pode direcionar o processo de formulação de hipóteses nas firmas.

Essas idéias de Loasby sugerem a identificação de um núcleo duro lakatosiano na firma, referente às diretrizes mestras dessa, e a de um cinturão protetor mais flexível, dependente do referencial interpretativo particular a cada subgrupo da organização. $\mathrm{O}$ desgaste de uma estrutura diante das anomalias encontradas no processo competitivo, por sua vez, sugere a possibilidade de revoluções científicas kuhnianas ocorrendo na direção da empresa.

Essas sugestões abrem espaço para as mesmas questões formuladas por Kuhn e Lakatos em suas teorias, agora aplicadas às firmas. Por exemplo, poderíamos investigar até que ponto existe em uma firma uma teoria empresarial hegemônica (um paradigma kuhniano) ou a convivência entre diversas teorias rivais disputando entre si, como na Ciência. Poderíamos ainda investigar se uma mu- dança paradigmática envolve substituição de executivos antigos por outros mais jovens ou se isso pode ser conduzido por este último grupo. Os paradigmas das firmas são incomensuráveis ou é possível falar em progressividade do "programa de pesquisa"?

Por fim, um problema a que dedicaremos a próxima seção deste trabalho indaga se existe alguma relação entre o tipo de procedimento metodológico adotado pela firma e o seu desempenho. Especificamente, firmas que adotam uma postura poperiana, fomentadora do espírito crítico, teriam desempenho diferente de firmas kuhnianas, mais presas a um paradigma específico?

\section{5_O racionalismo crítico no mercado}

A questão posta acima é respondida afirmativamente por Harper (1996). Em seu livro, a tentativa mais desenvolvida de resolver nosso problema, o autor desenvolve uma teoria da atividade empresarial que segue a tradição de Kirzner (1972), substituindo a qualidade de "alerta a oportunidades de lucros" deste autor por uma teoria do conhecimento e ação do empresário baseada na literatura de CC.

Harper supõe, com Popper, a existência de uma realidade objetiva, inde- 
pendentemente do que se passa na mente dos indivíduos. $\mathrm{O}$ acesso a essa realidade, no entanto, não é dada de forma direta, mas parte das situações de problemas com que os cientistas (ou empresários) se deparam. A formulação de problemas que dirigem o esforço cognitivo, por sua vez, é influenciada por teorias anteriores. O crescimento do conhecimento se dá pela formulação de conjecturas falíveis e sua exposição à refutação. Harper afirma que pelo menos parte dos agentes econômicos, na sua atividade empresarial, comporta-se da mesma forma que os cientistas: partem de problemas e submetem suas hipóteses a teste num processo de tentativas e erros. Prevê o autor que os empresários que adotam uma metodologia popperiana de aprendizado por conjecturas e refutações tendem, por seleção (não natural), a sobreviver no mercado.

As conjecturas dizem respeito a teorias de demanda latente, teorias de produção e teorias de estrutura de governança, sendo a primeira o campo que denominamos marketing, a segunda trata de explorar as desconhecidas possibilidades técnicas de combinação de fatores, e o terceiro tipo trata das soluções institucionais para os problemas de redução de custos de transação. As teorias são complementadas com hipóteses sobre as "cir- cunstâncias particulares de tempo e lugar" (Hayek), dando origem a previsões sobre os resultados da ação empresarial, que, por sua vez, influenciam o nível de lucros, se a hipótese for (provisoriamente) corroborada ou refutada.

O teste de hipóteses não consiste apenas no desempenho observado, mas assume várias formas, como avaliações de viabilidade de projetos, pesquisas de mercado externas, observação de concorrentes e assim por diante. Tal teste depende da metodologia adotada pelo empresário. A superioridade de agentes popperianos advém da maior habilidade de excluir teorias empresariais errôneas e evitar os prejuízos que surgem da sua adoção. $\mathrm{O}$ autor aponta uma série de características do empresário falsificacionista que são paralelas às prescrições de Popper. Alguns exemplos são: disposição ativa de buscar problemas, em contraposição ao agente neoclássico que aprende passivamente; sensibilidade a problemas, em vez de esquecimento ou tendência a ignorá-los; orientação ao cliente e não ao produto, falibilismo, ou reconhecimento que as hipóteses empresariais são conjecturais e a conseqüente cautela que disso decorre; pluralismo teórico ou busca de várias explicações para um fenômeno de mercado; busca ativa de desenvolvimento 
de novos produtos em vez de acomodação com soluções anteriores e, finalmente, uso extensivo do método crítico e a rejeição de hipóteses ad hoc para salvar teorias.

$O$ processo de teste aumenta o grau de objetivação das conjecturas empresariais: o que antes era um palpite ou intuição do empresário passa a ser passível de crítica por um time de profissionais, conforme as hipóteses sejam articuladas no processo de teste. Isso leva, em direções imprevisíveis, ao crescimento do conhecimento. O resultado do teste pode ser uma refutação ou uma corroboração. Como não se pode afirmar se um experimento foi decisivamente refutador ou não, vários graus de exigência no teste são feitos, conforme os custos dos dois tipos de erro: rejeitar uma hipótese correta ou aceitar uma hipótese falsa. Como "falsificacionista sofisticado", Harper dedica um capítulo inteiro à análise das dificuldades em determinar se uma hipótese foi refutada ou não. Estudam-se as falsas refutações e corroborações, a natureza theory-laden das evidências e a tese Duhem-Quine.

O "Problema de Hayek", quando estudado com o auxílio da Filosofia da Ciência, afasta Harper da concepção usual de aprendizado como acúmulo indutivo de informações. Todavia, como este último autor reconhece que o crescimento do conhecimento no mercado é um processo dinâmico de mudança endógena e indeterminista, conclui que nunca existe uma convergência para um estado de equilíbrio, negando assim a predominância das tendências equilibradoras enfatizadas pelos austríacos.

Apesar de ser a tentativa mais elaborada de tratar o agente econômico como um cientista, o trabalho de Harper falha num ponto importante. $\mathrm{O}$ autor foca sua atenção para o aprendizado por conjecturas e refutações na esfera dos planos dos agentes e não enfatiza o processo seletivo impessoal imposto pelo mercado. Pressupõe, além disso, que os agentes se comportam de fato como cientistas que seguem a metodologia popperiana. Mas como explicar o sucesso contínuo dos empresários vis-à-vis a estagnação da Ciência durante boa parte da sua história? A comunidade científica pode se ater a uma ideologia e barrar o progresso da Ciência através de dogmatismo e não-exposição de hipóteses à crítica. Por que isso não ocorre no campo empresarial?

$\mathrm{Na}$ verdade, observamos a maior continuidade do progresso no processo de mercado do que no de crescimento do conhecimento. Essa regularidade no mercado não depende unicamente, conforme 
defenderemos na próxima seção, da racionalidade dos agentes. De fato, o ambiente gerencial não é um exemplo clássico de condução racional das atividades. Conforme escreve Adams (1996, p. 12) no prefácio de seu livro de tiras cômicas:

Não sei por que a economia funciona, mas tenho certeza de que não é porque gente brilhante a está gerindo. Se você recapitular todas as atividades absurdas desenvolvidas pela gerência [das empresas], as idiotices de alguma forma se neutralizam produzindo coisas interessantes que você acaba querendo comprar [...].

$\mathrm{Na}$ próxima seção vamos defender a tese de que a existência nos mercados de um mecanismo seletivo mais impessoal do que em ciência resolve os problemas aludidos, sem recair em um modelo mecanicista sobre o funcionamento da Economia.

\section{6_ Uma nova solução para o "Problema de Hayek": a Epistemologia Evolucionária}

A tese de Harper sobre o crescimento do conhecimento leva a duas conclusões particulares que vamos criticar nesta seção. A primeira conclusão afirma que os agentes econômicos agem de fato como cientistas que seguem os preceitos metodológicos propostos por Popper. A se- gunda argumenta que, pelo fato de o processo de CC no mercado não ser determinista e depender das teorias dos empresários, não existe tendência ao equilíbrio. Uma versão evolucionária tanto da teoria do próprio Popper quanto do processo de mercado será agora usada para negar essas conclusões. Iniciaremos a discussão com o artigo clássico de Alchian (1950), que procura apontar para uma tendência ao equilíbrio no mercado sem que haja a necessidade de racionalidade "forte" por parte dos agentes. Em seguida, utilizaremos a Epistemologia Evolucionária de Popper (1972), Bartley $(1987,1990)$ e outros para fornecer uma alternativa à opinião de Harper.

O reconhecimento da importância das teorias dos agentes, embora corrija os defeitos de uma visão mecanicista, traz consigo o perigo do subjetivismo radical, que trata as expectativas e os planos dos agentes como um puro ato criativo, pouco limitado ou influenciado pela realidade subjacente dos fundamentos da Economia. Essa postura leva à rejeição de grande parte dos resultados clássicos da análise econômica em favor do historicismo. Por outro lado, a abordagem evolucionária, tanto em Economia como em Filosofia da Ciência, tem a vantagem de evitar os males dos dois extremos, preservando suas respectivas qualidades. 
Em Economia, o artigo pioneiro de Alchian (1950) serve para ilustrar o ponto. Nesse artigo, os resultados clássicos da microeconomia são preservados sem fazer uso dos exigentes postulados comportamentais e cognitivos usados por essa.

Mesmo que curvas de custo e receita marginal objetivas não sejam conhecidas, os agentes formulam seus planos tendo em vista seu conhecimento falível sobre os fundamentos da Economia. No caso extremo, os agentes podem tomar suas decisões de forma completamente aleatória. Os planos de ação das firmas que mais se compatibilizam com os fundamentos reais da Economia geram lucros positivos, acumulando capital para a continuidade dessas firmas, ao passo que aqueles mais distantes dessa realidade geram prejuízos, o que leva à eliminação destas últimas ou ainda à imitação das primeiras.

Com base nisso, Alchian conclui que o agente não maximiza nenhuma função explícita de lucros; o comportamento maximizador seria sem significado como um guia de ação. O critério real de seleção de firmas no mercado, na realidade, consiste em lucro realizado positivo (não máximo). Surge assim uma tendência à minimização de custos médios e maximização de lucros sem que se tenha conhecimento perfeito. O proces- so de aprendizado das firmas, dessa forma, seria análogo àquele descrito pela Teoria da Evolução:

The economic counterparts of genetic heredity, mutations, and natural selection are imitation, innovation, and positive profits (Alchian, 1950, p. 32).

O texto de Alchian mostra que pode existir uma tendência ao equilíbrio na ausência de conhecimento perfeito, uma vez que a realidade impõe limites à liberdade dos planos dos agentes. Essa tendência, por sua vez, deve ser explicada por um processo de aprendizado por tentativas e erros. Isso não nega, em absoluto, a importância do elemento criativo nas teorias empresariais. Sem a diversidade de planos rivais (mutação) enfatizada por Hayek, o processo de aprendizado dificilmente convergiria para um equilíbrio. Por outro lado, a existência de disposições do consumidor, possibilidades de produção e disponibilidade de recursos impõem limites à imaginação dos agentes.

Em Filosofia da Ciência, também existe o perigo de dois extremos. Ou acredita-se que a realidade é facilmente capturável pelos sentidos ou pela razão e, portanto, o conhecimento acumulado é certo; ou, diante da impossibilidade de provar com certeza alguma teoria, muitas vezes abandona-se a busca da verdade 
5 Ver Popper (1972),

Campbell (1987a, 1987b), Bartley $(1987,1990)$.

6 Ver, por exemplo, Boland (1998, p. 14) ou Bartley (1964).

7 Ver no mesmo livro a controvérsia sobre a possível circularidade desse argumento. $\mathrm{O}$ argumento de Hayek de que o fruto da competição não pode ser especificado antes dela (da mesma) ou ainda a acusação de circularidade da Teoria da Evolução são outras manifestações do mesmo equívoco justificacionista. em prol da descrição de aspectos históricos, sociológicos ou ainda retóricos da produção de conhecimento. Da mesma forma que em Economia, em metodologia a abordagem evolucionária escapa desses extremos. Nada mais natural, portanto, do que explorar esse paralelismo e unificar o argumento, como é feito pela Epistemologia Evolucionária. ${ }^{5}$

O dilema entre dogmatismo e relativismo em ciência que permeia grande parte da discussão metodológica é atribuído pelos autores dessa tradição ao justificacionismo, a crença de que todo o conhecimento racional deve ser demonstrado ou provado como verdadeiro. ${ }^{6}$ A prova de uma proposição científica, dada a necessidade de fundamentar os próprios postulados dos quais a proposição depende, leva ou a um regresso infinito ou, diante da afirmação de que certos axiomas são incontestáveis, à crença dogmática nesses axiomas. O relativismo que resulta do fracasso justificacionista, porém, pode ser evitado por uma posição que não identifica a racionalidade com a capacidade de se obter conhecimento certo, mas, sim, com a existência do espírito crítico. Essa posição nos é dada por Popper, cuja filosofia tem como peça central o falibilismo do conhecimento humano.

Ao contrário do popperianismo de livro-texto, popular entre os econo- mistas, o racionalismo crítico não exige que uma proposição seja indubitavelmente refutada pelos fatos para que a Ciência progrida. Sabemos que, quanto mais complexo o fenômeno a ser estudado, mais difícil se torna a obtenção de uma refutação clara. Tudo o que se afirma, ao contrário, é que, em um ambiente intelectual marcado pela tradição de crítica, o conhecimento progride mais do que em outro marcado pelo dogmatismo, independentemente da certeza da eficácia da crítica. Nos termos de Bartley (Bartley e Radnitsky, 1987), o racionalismo pancrítico estende o falibilismo popperiano à própria crítica. Uma refutação pode ser refutada. ${ }^{7}$

Tomemos um exemplo de Feyerabend (1975). Se Galileu tivesse aceito as então bastante razoáveis críticas feitas contra a hipótese de movimento terrestre, a astronomia não teria progredido. $\mathrm{O}$ argumento da torre, por exemplo, afirma que uma pedra abandonada do alto de uma torre não deveria cair na sua base se a Terra girasse. Contudo o argumento de Feyerabend supõe gratuitamente que, em um ambiente crítico, a hipótese galilaica nunca mais teria sido levantada, perpetuando-se assim o geocentrismo. Ora, isso é precisamente o que aconteceria se o espírito crítico fosse tolhido. Adotando-se uma postura falibilista, porém, o erro é 
inevitável, e temos que conviver com ele. Isso, todavia, reforça a necessidade de crítica, não a diminui. Com o surgimento da idéia de inércia, o argumento da torre perde sua força e cedo ou tarde seria criticado.

Utilizando o tema do nosso artigo na direção inversa (da Economia para a Filosofia da Ciência), o que a metodologia falibilista afirma é que o progresso da Ciência exige um ambiente competitivo (popperiano), e não um ambiente monopolista (kuhniano) (Bartley, 1990). No âmbito da Ciência, o argumento protecionista da indústria nascente feito por Kuhn é sujeito à mesma crítica que a ele se faz em Economia: a proteção gera acomodação, e não esforço por melhoras.

Retido o falibilismo - o núcleo da filosofia de Popper -, o programa do racionalismo crítico defende a busca de um ambiente intelectual o mais permeável à crítica possível. Para tal, as proposições científicas devem ser objetivadas, ${ }^{8}$ tratadas como objetos em si, dissociados dos aspectos subjetivos de sua criação, de maneira a ser passível de análise por uma comunidade independente (Popper, 1972).

A Epistemologia Evolucionária, herdeira dessa tradição falibilista, vê o crescimento do conhecimento em diversos contextos como um processo de seleção de hipóteses objetivas por um mecanismo de eliminação de erros.
Conforme nota Vanberg (1993, p.185):

Evolutionary epistemology is based on the assumption that from natural selection to the growth of scientific knowledge the same basic principle of trial and error-elimination can be found operating. All organisms are, as Popper puts it, constantly engaged in problem-solving which "always proceeds by the method of trial and error: new reactions, new forms, new organs, new modes of behavior, new bypothesis, are tentatively put forward and controlled by error-elimination".

Nos diversos campos estudados, como na Biologia, na Ciência ou nos mercados, o método evolucionário, mesmo com suas diferenças, é composto de três fases: variação, seleção e reprodução (Campbell, 1987a; Popper, 1972). A variação assume forma de mutações genéticas, teorias rivais e planos empresariais. A seleção é dada pela competição pelos recursos, pela crítica e pela realização de lucros e prejuízos. As "soluções" sobreviventes são, por sua vez, transmitidas e submetidas novamente a teste.

O valor dessa abordagem consiste no fato de que reconhece o caráter provisório de todo o conhecimento e, ao mesmo tempo, enfatiza o processo de eliminação de erros, em vez de se refugiar na mera descrição histórica da atividade de $\because \cdot \cdots \cdot \cdots \cdot \cdot \cdot \cdot \cdot \cdot \cdot$

8 O conhecimento é objetivo no sentido de ser um objeto do mundo 3 (Popper, 1972): Popper faz uma analogia com uma teia de aranha. É um produto do animal, mas pode ser estudada independentemente de seu criador. 
solução de problemas. Evita assim tanto o positivismo quanto o relativismo e o historicismo. Ora, essas duas posturas são justamente aquelas que queremos evitar na solução do problema do conhecimento de Hayek. Vejamos como contornar esses dois extremos.

Em relação ao primeiro, Vanberg (1993) nota que os métodos evolucionário e de maximização neoclássico têm como objetivo descrever como a eficiência e a adaptação surgem no mercado. No entanto, podemos observar a radical diferença nos métodos empregados: na teoria microeconômica tradicional, o erro não tem sua importância devidamente notada. Os agentes conhecem a estrutura do problema, e o conhecimento é perfeito ou a incerteza é consideravelmente restrita. Neste mundo a diversidade (variação) não tem função: os produtos são homogêneos, e a diferenciação resulta em ineficiência. No método evolucionário, ao contrário, a ignorância e o erro desempenham papéis preponderantes. Se as preferências não são conhecidas, a variação de produtos desempenha papel fundamental no processo de descoberta. Quanto mais variações, maior a probabilidade de uma solução sobreviver ao mecanismo de teste. Devemos contar com o processo de variação e seleção para fazer o conhecimento crescer. Não se pode então ignorar a importância da atividade em- presarial. Em relação ao segundo extremo, o reconhecimento do caráter criativo do conhecimento empresarial não implica no subjetivismo radical, já que os planos de ação inviáveis tendem a ser eliminados pela realização de prejuízos, o que limita a liberdade das teorias empresariais.

Em que medida existe então uma tendência ao equilíbrio se ao mesmo tempo convivem forças que eliminam erros e forças que introduzem novidades? A resposta nos leva a analisar algumas diferenças entre os esquemas evolutivos existentes nos diversos campos de estudo mencionados, diferenças essas que explicam tanto a existência da tendência ao equilíbrio quanto a velocidade da adaptação. Duas dessas diferenças básicas se referem a:

_ o grau de aleatoriedade das tentativas;

_ a natureza do processo seletivo.

Quanto ao primeiro item, Campbell (1987b) enfatiza que as variações são aleatórias (blind variation). Em Biologia, isto é importante para eliminar qualquer traço de explicação teleológica na teoria. $\mathrm{Na}$ esfera epistemológica, o caráter "cego" das tentativas se refere ao fato de que não se sabe a priori, na concepção falibilista, a adequação da solução ao problema proposto: a variação é cega em rela- 
ção à solução. A concepção indutivista de acúmulo de informações, por outro lado, é lamarckiana, já que se sabe que tipo de informação deve ser buscada.

Contudo, aqui, bem como nas conjecturas empresariais, a ação humana é propositada. As tentativas não são aleatórias, mas direcionadas para a solução de problemas, conforme enfatiza Alchian no artigo que discutimos. $\mathrm{O}$ modelo aleatório foi usado por esse autor apenas como ponto de partida. No campo da Economia, como não há qualquer restrição à existência de teleologia na formulação de hipóteses, o caráter proposital, embora cego, das tentativas, torna a atividade coordenadora no mercado muito mais plausível; a adaptação pode existir e ter uma velocidade muito maior do que na seleção natural. Entretanto, em razão do mesmo caráter cego, o resultado da coordenação no mercado é indeterminado, a sociedade é "resultado da ação humana, mas não da intenção humana", conforme afirmam Adam Ferguson e Hayek.

Existem também diferenças relacionadas ao segundo item - a natureza do processo seletivo. Popper em várias ocasiões enfatizou que na Ciência devemos deixar as idéias morrerem em nosso lugar. Em Biologia, o fracasso significa morte por seleção natural. Em ciência, no entanto, podemos aprender com os nossos erros e redirecionar os esforços em direção a outras hipóteses. Isso gera enorme economia de custos em relação à seleção natural, já que não se desperdiça o capital humano que formulou a hipótese eliminada. Além disso, o processo de experimentação nos modifica, tornandonos mais bem preparados para enfrentar os problemas. Mas isso depende da nossa adesão espontânea a regras metodológicas que professem o racionalismo crítico. $\mathrm{O}$ cientista pode se ater a um paradigma de forma rígida e dogmática, de modo a eliminar em absoluto a eficácia do processo de seleção de hipóteses. $\mathrm{Na}$ verdade, com isso se altera a natureza do processo seletivo, mas numa direção diferente daquela do crescimento do conhecimento.

No mercado, por outro lado, o processo seletivo não é tão impessoal como em Biologia nem tão dependente da escolha dos agentes como em ciência. Harper enfatizou a seleção (subjetiva) de hipóteses mercadológicas feita pelos empresários. Mas estes também estão sujeitos a um processo seletivo impessoal: o critério de perdas e lucros. A insistência no erro leva à perda de capital, à falência e à dificuldade de obter novos financiamentos. A "realidade subjacente" das preferências, da ação dos outros agentes, da 
disponibilidade de fatores impõe limites à liberdade humana. Essa limitação ao poder de escolha dos agentes impõe um ritmo menor à evolução no mercado (perde-se algum capital), mas a torna menos passível de estagnação (a insistência no erro não fica sem punição).

Uma das figuras centrais da Epistemologia Evolucionária, Bartley III, que foi aluno tanto de Popper quanto de Hayek, explora alguns paralelismos entre as teorias desses autores. Em particular, Bartley utiliza a idéia de Popper sobre o caráter objetivo do conhecimento e como isso leva ao "crescimento do conhecimento" para ilustrar que esse ocorre na teoria hayekiana do mercado, apontando a importância da "divisão do conhecimento" desse autor. Para Bartley, o conteúdo de uma teoria pode ser descrito pelo conteúdo lógico (suas conseqüências lógicas) ou pelo seu conteúdo informativo, que abarcam todas as proposições que potencialmente a contradigam. O conteúdo lógico é claramente infinito. Bartley argumenta que o conteúdo informativo também o é: inclui, por exemplo, as proposições pertencentes a teorias rivais ainda não existentes (Bartley, 1990, p. 34; Popper, 1972). Dentro do conteúdo informativo da teoria mecânica de Newton, está a Teoria da Relatividade, de Einstein, mesmo que essa teoria não existia na época de Newton. A conclusão evidente que Bartley aponta é o caráter "insondável" (unfathomable) de todo o conhecimento, ou seja, não podemos acessar todas as conseqüências de uma teoria. Uma teoria foge ao controle do cientista que a criou não apenas por "distorções" adicionadas por outros, mas porque o próprio autor não entende o significado de sua própria teoria.

A Física é repleta de exemplos de cientistas que mostram desagrado quando a eles é explicado o significado de um aspecto da sua própria teoria. Como não entendemos as teorias, não podemos controlar nem prever o crescimento do conhecimento. Isso é perfeitamente paralelo às idéias de Hayek sobre o funcionamento do mercado. Bartley (1987, p. 425) coloca a questão em termos do paralelismo entre o falibilismo de Popper e o de Hayek:

I learnt from Popper that we never know what we are talking about, and I learnt from Hayek that we never know what we are doing.

Em ciência, a objetivação do conhecimento permite que as idéias morram em nosso lugar, aumenta o grau de precisão e torna público o conhecimento. Isso é necessário para submeter a hipótese a teste e aumentar o desenvolvi- 
mento da Ciência. No mercado ocorre o mesmo. Conforme ensina Hayek, a ordem espontânea impessoal do mercado realiza uma tarefa de coordenação sem que saibamos os propósitos e planos de cada pessoa, cada indivíduo colabora na execução de planos de milhares de pessoas que ele jamais conhecerá. Isso leva a significativa economia de conhecimento. ${ }^{9}$ Bartley aponta que, para o conhecimento (e a riqueza) no mercado crescer, é necessária uma objetivação ou distanciamento dos produtos, da mesma forma que se objetivam as idéias.

Nessa direção, o autor critica a idéia de Marx sobre alienação, afirmando que o conhecimento objetivo é autônomo no exato sentido criticado por este último autor: ele "foge ao nosso controle, ultrapassa nossas expectativas e anula nossos cálculos". Se o conhecimento e a economia devem crescer, a "alienação" ou estranhamento seria condição sine qua non.

\section{7_ Resumo e conclusão}

O objetivo deste trabalho foi aplicar a literatura do "crescimento do conhecimento" (CC) à análise econômica. O estudo do crescimento do conhecimento teórico pode ser utilizado para estudar o crescimento do conhecimento prático formulado pelos agentes econômicos. Iniciamos enfatizando, seguindo Hayek, a importância do estudo do crescimento do conhecimento dos agentes para que se possa obter uma explicação satisfatória do funcionamento dos mercados. Em seguida criticamos a Economia da Informação por utilizar uma teoria de aprendizado que sofre dos defeitos apontados por Popper, Kuhn, Lakatos e Feyeraband. Para resolver o "Problema de $\mathrm{Ha}$ yek", estudamos como Loasby utiliza as idéias da metodologia no estudo da teoria das firmas. Posteriormente expusemos como Harper utiliza, explicitamente e de forma extensiva, as idéias de Popper para formular uma teoria da ação empresarial. A interação entre as teorias e a realidade subjacente aos mercados foi estudada com o auxílio da abordagem evolucionária iniciada pelo trabalho de Alchian. Concluímos o trabalho com a unificação da teoria de processo de mercado com uma derivação dos escritos maduros de Popper, a chamada Epistemologia Evolucionária, capaz de fornecer uma solução mais satisfatória para o "Problema de Hayek".

A seguir listaremos algumas conclusões a que chegamos no texto: $\cdots \cdot \cdot \cdot \cdot \cdot \cdot$

Note a semelhança com

Adam Smith: este fala da

divisão do trabalho, e Hayek sobre divisão do conhecimento. 
_ A Economia deve estudar não apenas os estados de equilíbrio, mas o processo de mercado, que pode levá-lo ou não a uma tendência ao equilíbrio. Para isso é importante estudar o crescimento do conhecimento dos agentes, conhecimento esse que informa os planos de ação.

_ Para estudar os planos e as ações dos agentes econômicos, podese utilizar a teoria de CC, pois tanto em ciência quanto no mercado se estuda o "crescimento do conhecimento". Deve-se distinguir, no entanto, o conhecimento teórico, relevante no primeiro, do prático, relevante no segundo. Este último exige constante revisão das teorias dos agentes, uma vez que a realidade investigada é mutável.

_ A competição deve ser valorizada para descobrir os fatos que a teoria neoclássica considera como dados. A atividade competitiva no mercado gera um processo de descoberta desses fatos.

_ O aprendizado nos modelos de informação assimétrica assume caráter indutivista, pré-popperiano. Esse caráter é inerente à ma- tematização do aprendizado dos agentes, já que aquilo que pode ser conhecido deve ser especificado de antemão.

_ Pode-se utilizar a teoria do CC para estudar a coordenação do esforço de aprendizado dentro da firma e o objeto desse aprendizado como meio de buscar lucros. A firma pode ser considerada um conjunto de potencialidades teóricas que busca a resolução de problemas mercadológicos.

_ Pode-se desenvolver a teoria da atividade empresarial incorporando a ela a teoria de CC, enxergando o empresário como um falsificador popperiano, estudando as teorias empresariais, os sistemas de testes de hipóteses e a evolução do conhecimento empresarial. Algumas disposições críticas dos empresários levam a maior probabilidade de sucesso desses, pois se aprende com os erros. Pode-se também utilizar temas lakatosianos e kuhnianos para estudar a inércia ou rigidez na mudança das estruturas teóricas dos empresários.

_ Uma maneira de lidar com a incerteza no mercado e o preponderan- 
te papel do erro e da ignorância dos agentes é utilizar modelos baseados na Teoria da Evolução, em vez de utilizar modelos mecanicistas como a Economia vem fazendo nos últimos cem anos.

_ Inovações, critério de perdas e lucros e crescimento dos ativos da firma são os equivalentes econômicos à mutação, à seleção e à reprodução da Biologia.

_ A Epistemologia Evolucionária pode generalizar a microeconomia, explicitando em que casos existe uma tendência ao equilíbrio ou não, segundo variáveis como a estabilidade do ambiente, o grau de competição que resulta em hipóteses rivais, ou, ainda, o caráter automático ou subjetivo de seleção de hipóteses.

_ O caráter objetivo do conhecimento leva a maior desenvolvimento do conhecimento e ao mesmo tempo à impossibilidade de controlar conscientemente o processo de CC. 


\section{Referências bibliográficas}

ADAMS, S. O Princípio Dilbert. Rio de Janeiro: Ediouro, 1996.

ALCHIAN, A. Uncertainty, evolution and economic theory. In: Economic Forces at Work. Indianapolis: Liberty Press, 1950.

BARBIERI, F. Uma bistória do debate do cálculo econômico socialista. 2004. Tese (Doutorado em Economia) - FEA, Universidade de São Paulo, São Paulo, 2004.

BARTLEY III, W. W. Rationality versus the Theory of Rationality. In: BUNGE, M. (Ed.). The critical approach to Science and Philosophy.

Londres: Collier-Macmillan, 1964

BARTLEY III, W. W. Unfathomed knowledge, unmeasured wealth -

On universities and the wealth of nations. La Salle: Open Court, 1990.

BARTLEY III, W. W. RADNITZKY, G. Evolutionary epistemology, rationality and the Sociology of Science. La Salle: Open Court, 1987.

BOLAND, L.A. The foundations of economic method. Londres: George Allen \& Unwin, 1982 Disponibilizado na internet em 1998
CAMPBELL, D. Evolutionary Epistemology. In: BARTLEY III W. W.; RADNITZKY, G. Evolutionary Epistemology, rationality and the Sociology of Science. La Salle: Open Court, 1987a.

CAMPBELL, D. Blind variation and selective retention in creative thought as in other knowledge processes. In: BARTLEY III, W. W.; RADNITZKY, G.

Evolutionary epistemology, rationality and the Sociology of Science. La Salle: Open Court, 1987b.

FEYERABEND, P. Contra o método. Rio de Janeiro: Francisco Alves, 1975.

FRANSMAN, M. Information, knowledge, vision and theories of the firm In: DOSI et al., Technology, organization and competitiveness. Oxford University Press, 1998.

GROSSMAN, S. J.; STIGLITZ, J. E. Information and competitive price systems. American Economic Review, v. 66, n. 2, 1996.

HAYEK, F. A. Competition as a discovery procedure. In: HAYEK, F. A. New studies in Philosophy, Politics and Economics. Londres: Routledge, 1978.
HAYEK, F. A. [1937]. Economics and knowledge. In: HAYEK, F. A. Individualism and economic order. Chicago: Chicago University Press, 1980a.

HAYEK, F. A. [1945]. The use of knowledge in society. In: HAYEK, F. A. Individualism and economic order. Chicago: Chicago University Press, 1980b.

HAYEK, F. A. [1946]. The meaning of competition. In HAYEK, F. A. Individualism and economic order. Chicago: Chicago University Press, 1980c.

HARPER, D. Entrepreneuship and the market process - an inquiry into the growth of knowledge. Londres: Routledge, 1996.

KIRZNER, I. Competition and entrepreneurship. Chicago: The Chicago University Press, 1972.

KUHN, T. S. A estrutura das revoluções cientificas. São Paulo: Perspectiva, 2000.

LAKATOS, I.; MUSGRAVE, A.

(Ed.). Criticism and the growth of knowledge. Cambridge: Cambridge University Press, 1970
LAVOIE, D. Rivalry and central planning. Cambridge: Cambridge Economic Press, 1985

LOASBY, B. Organization, competition and the growth of knowledge In: LANGLOIS, R (Ed.). Economics as a process. N. York: Cambridge University Press, 1986.

LOASBY, B. Institutional stability and change in Science and the Economy In: MÄKI, U. (Org.). Rationality, institutions \& economic methodology. Londres: Routledge, 1993.

NELSON, R.; WINTER, S. An evolutionary Theory of Economic Change. Cambridge: The Belknap Press of Harvard University Press, 1982.

POLANYI, M. Personal knowledge. Chicago: The University of Chicago Press, 1958.

POPPER, K. R. A lógica da pesquisa científica. São Paulo: Cultrix, [s. d.]

POPPER, K. R. On clouds and clocks. In: POPPER, K. R.

Objective knowledge. Oxford: Clarendon Press, 1972. 
STIGLER, G. J. The economics of information. Journal of Political Economy, v. 67, 1961.

THOMSEN. E. Prices and knowledge. Londres: Routledge, 1992.

VANBERG, V. Rational choice, rule-following and institutions: An evolutionary perspective. In: MÄKI, U. (Org.). Rationality, institutions \& economic methodology. Londres: Routledge, 1993.

$\ldots \ldots \ldots \ldots$

- Agradeço aos pareceristas

- anônimos os valiosos comentários

- e ao Prof. José Albertoni de

- Pinho a revisão do texto.

E-mail de contato do autor:

- fabiusbarbieri@gmail.com

Artigo recebido em março de 2006

e aprovado em julho de 2006.

...............

nova Economia_Belo Horizonte_16 (3)_507-534_setembro-dezembro de 2006 